\title{
Using Audio-Visual Aids and Computer-Assisted Language Instruction (CALI) to Overcome Learning Difficulties of Sound System in Students of Special
} Needs

\author{
Sadeq Ali Saad Al- Yaari (Corresponding author) \\ Independent Researcher, Dept. of English, College of Arts, King Saud University (KSU) \\ Riyadh, Kingdom of Saudi Arabia \\ E-mail: prof.sadeq@gmail.com
}

Received: October 28, 2013 Accepted: November 10, 2013 Published: December 12, 2013

doi:10.5296/jsel.v1i2.4742 URL: http://dx.doi.org/10.5296/jsel.v1i2.4742

\begin{abstract}
Background \& Objectives: Audio-visual aids and computer-assisted language instruction (CALI) effects are strong in teaching language components (sound system, grammatical structures and vocabulary) to students of special needs. To explore the effects of the audio-visual aids and CALI in teaching sound system to this class of students by speech language therapists (SLTs), an experiment has been undertaken to evaluate their performance during their study of the sound system course.

Methods: Forty students (males and females) of special needs at al-Malādh school for teaching students of special needs in Dhamar (Yemen) range between 8 and 18 years old underwent this experimental study while they were studying language sound system course. Pre-and-posttests have been administered at the begging and end of the semester. Students' treatment was compared to a similar group (control group) of the same number under the same environment. Whereas the first group was taught using audio-visual aids and CALI, the second was not. Students' performances were linguistically and statistically evaluated.

Results \& conclusions: Compared with the control group, the treatment group showed significantly higher scores in the posttest $(72.32 \%$ vs. $31 \%)$. Compared with females, males scored higher marks (1421 vs. 1472). Thus, we should take the audio-visual aids and CALI into consideration in teaching sound system to students of special needs.
\end{abstract}


Keywords: Language Components, Sound system, Audio-Visual Aids, CALI, Students, Special Needs, SLTs.

\section{Introduction Chapter}

\subsection{Introduction}

Audio-visual aids and CALI are associated with the improvement of language skills be it receptive skills or productive skills or even language components (Gilakjani, 2012). These educational aids are found to be useful not only for normal students, but also for students with special needs (Iram, 2012; Kirk, et al., 2012). Explaining the reasons behind the new trend, Kirk and his colleagues have rightly observed: "Such tests, in which acoustic variability is highly constrained, may not accurately reflect spoken word recognition abilities under more natural listening situations." (Kirk, et al., 2012: p. 455)

To study how audio-visual aids and CALI affect the ability of the normal students and those of special needs, improve their productive skills, some researchers went further to investigate the process of recognizing the word in the brain before it is articulated. According to them, articulation is the ice-berg of the pronunciation process which is preceded by brain process Bradham (2012). The operation takes place, according to Bradham when "Outer hair cells provide mechanical feedback into the organ of Corti, thus enhancing the input to the inner hair cells, which predominantly send information to the central nervous system." (Bradham, 2012: Abstract)

Such findings inspired researchers to ask legitimate and reasonable questions relating to the ways information are processed in the brain and the relationship between motion representation and the visual motion system (Pavan \& Baggio, 2013). More importantly, how and where does this process take place in the brains of students with special needs, especially when it comes to matters relating to deep/ surface reading for example (Wolf, et al., 2012) or those concerning Braille-reading and the way to understand issues like shape and space by blind students (Klingenberg, 2012). Onnis \& Thiessen (2013)'s findings suggest that mechanisms of statistical sequential learning are implicated in language across the lifespan, and experience with language may affect cognitive processes and later learning. Others went further by investigating not only the patients, but also the role of the parents and other people around the child which results "in greater exposure to the majority language. (MacLeod, et al., 2013: p. 132)

New trends of the research in this field started to focus on physicians and nurses and the way they read, write, etc. (Khaliq, et al., 2012; Peinhardt \& Hagler, 2012).

Furthermore, scientists established a new trend whereby language aspects could be linked together. The study of Diaz-Maurin \& Giampietro (2013) investigated the impact of grammar for assessing the performance of power-supply systems. Having the nuclear energy and fossil energy compared to each other, the researchers concluded that when considering internal constraints, nuclear energy requires about twice as much power capacity and 5-8 times more 
labor. Diaz-Maurin and his colleague confirmed that things do not improve for nuclear energy when looking at external constraints which may explain the difficulties faced by nuclear energy to gain interest from investors. Despite of the fact that audio-visual aids and CALI made better progress in the levels of students, some researchers are still believe in the original methods as effective means through which students can acquire language skills, notably reading, listening and writing (Devimeenakshi \& Maheswari, 2012). Additionally, pedagogical-based aids were present with more theoretical views but not with more practical use. Consistent with the existing literature on other audio-visual aids and CALI, at least film is common in the field of education (Swimelar, 2013). Knowing the prevalence of boards, notably for teaching students of special needs supplements educational interpretation and can overcome the learning difficulties they suffer from? Many studies have been conducted in this field like Gessesse \& Sileshi, 2013)'s study whose purpose was to examine visual semiotic signs and bill-boards and their communication implications, especially if they are used for patients. It appears to in favor of this that Gessesse and her friend have forwarded the following notification: "all the visual semiotic signs on all these billboards would give a much wider picture of the types and applications of visual semiotic signs. For another, it would also provide greater opportunities to identify the genres of messages represented through these visuals semiotic signs" (Gessesse \& Sileshi, 2013: p. 246)

Students of special needs frequently encounter learning difficulties related to audio, visual or audio-visual texts. Some difficulties can be subtle but can seriously influence the students' ability to learn. The article of Brown et al., (2013) proposes that differing types of annotation offer a powerful and flexible technique for transferring the benefits of graph-based diagrams, as well as for reducing disorientation while moving around the graph and for tackling some of the inherent disadvantages of using sound. According to Brown and his friends, graph annotation may be performed automatically, creating a graph that evaluation shows requires less mental effort to explore and on which tasks can be achieved more effectively and more efficiently. Such results received high support from Chen \& Yen (2013) who concluded their study by providing insights on the design and instruction, not only for written text reading, but also for online reading. The technological features of reading software that can be used for word recognition have not been explicitly investigated, but they may not be comparable because some techniques do not follow the same distinctive features and other qualities of others. The study of Damoiseaux, et al., (2012) may be a valuable source of information for refining our understanding of some of this software in general. Damoiseaux and his friends discussed the automatic reading of anti-neutrophil cytoplasmic autoantibody (ANCA-Slides). The purpose of the research team was to evaluate the AKLIDES System. The team emphasize that the results are promising in that the pattern recognition software may play an important role in ANCA-associated vasculitis diagnostics. Some researchers investigated the idea of how blogs could be used for language purposes. The article of Álvarez (2012), for example, presents a study on the best ways of using blogs as a tool to improve students' reading and writing skills. The results showed that blogs are reliable tools for the improving students' productive skills.

A total of 186 English as second language (ESL) elementary school subjects underwent the 
study of Ismail, et al, (2012). The aim of the study was to dis/prove whether or not using technology helps ESL learners improve their reading and writing skills. There are significant differences in the performances of the ESL students. This can be obviously seen in the outcomes of the qualitative and quantitative analyses of the scores. According to Ismail and his team, technology might play crucial role in assisting students to learn reading and writing skills. Other significant results, the researchers added, revealed that technology helped teachers in assigning extracurricular activities and communicating with students.

There has been growing interest recently in the use of multimedia as audio-visual aids to decode information and facilitate messages from high-dimensional scientific facts and present them to English as foreign language (EFL) students. The study of Fuenzalida \& Sjöberg (2012) employed a support vector machine-based T.V approach to teach EFL students language skills, especially for young learners. Such results were supported by the study of Ahmed (2012). Gower \& McDowall (2012) assessed the role of interactive video games on educating children during the study of language skills and/ or language components. Eleven subjects ( 9 children and 2 music specialists) underwent the experiment. The two researchers concluded their study by recommending the use of audio-visual aids and computer-assisted/ aided language instruction (CALI) as useful educative means when they are used for teaching EFL students.

In their study, Anson \& Schwegler (2012) aimed at investigating tracking mind's eye technique. Anson and his colleague wanted to examine the usefulness of this strategy to be implemented for improving foreign language students' reading skill. Nevertheless, the study also highlighted the need for further research into how to improve such technique in composition studies, especially at the intersection of writing. Although currently only a few randomized controlled studies investigated the efficacy of tracking the movement of the eye, such outcomes received a great support by many researchers in the field who conducted similar studies. (Henderson \& Luke, 2012; Perea, 2012)

Audio-visual aids and CALI had a strong internal and external consistency on the performance of the students. The test-retest and intra- and inter-rater reliabilities were shown to be adequate when it comes to talk about the effectiveness of the audio-visual aids and CALI, and the same thing applies to discriminant validity which was good in most of the conducted studies. For new techniques related to audio-visual aids and CALI, different outcomes were found: apart from one correlation, the scores on tests assessing a language skill and/ or a language component correlated significantly with outcome measures of similar methods. One of those methods is graphic organizer method designed by Manoli \& Papadopoulou in 2012. According to the researchers, the study constitutes an attempt to shed light on the research evidence regarding the effectiveness of graphic organizer on text learning and the various types of graphic organizers, which use different conventions to communicate information and are classified in various ways. The researchers finished their study by recommending ways of integrating them in reading lessons, touches on the issue of strategy instruction and its effects on language learning and leaves room for further exploration. 
Using the Italian pseudo homophones that contained atypical letters or letter sequences in more complex items than those commonly employed within the information-processing approach, but still easier than those used in intelligence tests, Peressotti \& Colombo (2012)'s study analyzed how the lexical contribution to non-word reading can be evaluated. The study involved analyzing the outcomes of three experiments and concluded that the Italian pseudo homophones did not benefit from an orthographic lexical contribution. These pseudo homophones, according to the researchers, were mainly processed through the interaction system between the sub lexical mechanisms and the phonological output lexicon. Moreover, "Phonological lexical knowledge can affect the phoneme level through reciprocal connections. Italian pseudohomophones, as well as control matching nonwords, do not activate the orthographic input lexicon; the pseudohomophones' advantage originates within the interactive activation system between the phonological output lexicon and the phonemic buffer." (Peressotti \& Colombo, 2012: p. 467)

In fact, activation system is not limited to phonological output lexicon and the phonemic buffer; rather, it expands to include semantic activation which is found to be automatic (Augustinova \& Ferrand, 2012). The aim of Wild's study (2013) was to determine the way students of special needs (namely those who suffer from visual impairments) understand and recognize sounds to assess their performances. The reliability study used a pre-and-posttest design which was administered to identify the conceptual understanding of the subjects under investigation. The researcher concluded discussing the challenges face students of special needs who are found to have conceptual misconceptions of sound prior to instruction and that their understanding changed on completion of the inquiry-based curriculum. Summarizing the most important finding, Wild has clearly stated that: "the students with visual impairments had misconceptions and an incomplete understanding of sound." (Wild, 2013: p. 114)

The study, according to Wild, yielded a methodology to teach sound, a mandated science topic within the standards that appears to be effective for students with visual impairments. The properties of the Sound-driven enhancement and their effects on the vision were studied by Pérez-Bellido, et al., (2013) in a sample of participants who performed a simple visual speeded detection task on Gabor patches of different spatial frequencies and contrast values, presented with and without accompanying sounds. According to the researchers, the aim was to disentangle detection-level from decision-level contributions. An examination of construct validity was undertaken on the subjects recruited in the study. Results have been assessed on all related measures. Findings revealed that interactions at detection stages and at decisional processes in response selection that contribute to audio-visual enhancement can be separated online and express on partly different aspects of visual processing.

Syllabification problems are common problems in melody and non-melody languages that are essentially determined by the position of the syllable in the word, but also by the extent of the ensuing EFL learners' response. The study of Liu, et al., (2013) sought to examine the syllable language models for Mandarin speech recognition, in order to further test the hypothesis of exploiting character language models. The treatment protocol included 2.8 billion words (equivalent to 4.3 billion characters). The results of the research team supported 
the hypothesis that character or syllable sequence models are useful for improving Mandarin speech recognition performance.

However, sight word identification motivated Pike (2012) to examine the effects of certain related strategies on the performance of Piano students. Linguistically, the word consists of syllables (phonemes or sounds). Separating the morphemes of the word (forms of sounds) gives only vowels and consonants that have meaningless meanings. The prevalence of the combined letters to give the meanings based on the positions wherein they are assigned when recognizing a visually presented word determines the significant of the letter as well as the phonemes and even the morphemes. Such theory was examined by Taft \& Kresb-lazendic (2013) in three experiments and was stratified by non-words created by transposing the two medial consonants of a dissyllabic base word (e.g., napkin, sermon). When the three experiments' results were considered simultaneously, findings revealed that "TL" non-words in a lexical decision task was shown to be lower when the medial consonants of the base word formed a complex coda (e.g., the rim of sermon) than when they comprised a separate coda and onset (e.g., the $\mathrm{p}$ and $\mathrm{k}$ of napkin). The same result was shown in false positive responses to non-words when their visibility was degraded through masking. In addition, these TL effects were just as strong for non-words like napkin as they were for non-words whose medial consonants formed a complex coda like walrus, but whose base word was syllabified between those consonants (e.g., the 1 and $r$ of walrus).

Feedback from using modern audio-visual aids and CALI including technological devices like iPads indicated that high level of understanding the lessons are observed. The study of SuHua, et al., (2013) aimed to investigate the role of the above mentioned technique to help learners identify letters and sounds. The researchers concluded that the use of the iPads helped these leaners learn independently and encouraged the development of positive attitudes as well as technology skills. Commenting upon some of what the study found, SuHua and his colleagues have rightly observed: "The students gradually developed confidence and were able to identify the alphabetic letters, and to distinguish the differences between letters and sounds by hearing, seeing, playing, and writing letters and words in meaningful ways. We also assisted the students mastering other literacy practices, such as sight word identification, phoneme segmentation, and phonics blending by using the iPad." (SuHua, et al., 2013: p.26)

Sigrist, et al., (2013) addressed the importance of technical display as means through which motor learning is enhanced, recommending using these audio-visual aids in addition to CALI. According to the research team, such audio-visual aids and CALI are important means that should be extensively used for teaching language skills due to their usefulness that can be clearly seen in the EFL students' multimodal feedback.

Augustinova \& Ferrand (2012) attempted to answer the question proposed by many researchers on whether or not construing words as meaningless symbols eliminate semantic activation. Conducting two experiments to in/validate such suggestion, Augustinova and his friend found that construing words as meaningless symbols does not eliminate, or even reduce semantic activation. 


\subsection{Aims of the Study}

This study attempted to test the main and interaction effects of using audio-visual aids and CALI in the performance of students of special needs in sound system. To this end, the researcher aims to find answers for the following questions:

1. What are the audio-visual aids and CALI that can be used for teaching students of special needs language in general and sound system in particular? To what extent can SLTs benefit from them when teaching this class of students? What are the best methods that can be effectively used for implementing these educative aids in a way that guarantee improving students of special needs' performances.

2. Compared with those who do not use them, do audio-visual aids and CALI make any difference when they are used for teaching sound system to students of special needs? Are there any results of other studies that agree or contradict the findings of the present study?

\subsection{Methodology}

Eighty students of special needs of both sexes (age ranges between 8-18 years old) were enrolled in this experimental study. The subjects were randomly divided into two groups; each group consists of 40 students. Nearly all students suffer different types of aphasias. They underwent a course on sound system, for a semester (4 months) at al-Malādh school for teaching students of special needs in Dhamar city, republic of Yemen. The purpose of the study was to examine the effectiveness of audio-visual aids and CALI when they are used for teaching language components in general and sound system in particular. Before and immediately after the first sounds' lesson, the subjects under investigation performed a pre-test and at the end of the semester, another post-test was administered to them by their SLT who was teaching the two groups at the same school. In between the treatment, the first group studied using audio-visual aids, while the second group studied using ordinary methods (chalk and black boards). Outcomes of the two tests were linguistically and statistically assessed. In this regard, social program for social sciences (SPSS) was implemented to describe the frequencies.

\section{Analysis}

2.1 Using audio-visual aids and CALI to teach students of special needs language components in general and sound system in particular

Educative aids are frequently used in language practice to help students learn very well. Recently, psychoneurolinguists and speech language therapists (SLTs) have realized that using these aids is of special importance to students of speech needs. These divided the practical part of these educational aids into two broad categories:

1. Conventional aids.

2. Computer learning in language teaching.

A very legitimate question that poses itself in this regard is the following: 
Why do we use aids in language teaching in general and what are the benefits of using them for students of special needs? To answer such reasonable questions, one needs to understand that aids can be used for many language purposes. Some of these purposes can be listed as follows:

1. Attracting attention.

2. Maintaining attention.

3. Clarifying concepts and meanings of words and utterances.

4. Increasing chances of remembrance.

5. Time saving (1 picture is worth 1000 words).

6. Adding varieties to class activities.

7. Compensation for the lack of experience in teachers (e.g., bringing pictures for throat to compensate for his inability to draw).

8. Individualizing learning and teaching (e.g., giving students cassettes to be listened to at home or program instruction which takes forms like the book, for example, which is the simplest form and which contains some forms that have some bits of information and each bit of information has its feedback in the margins, etc.

9. Involving learners: Either by asking them to participate in class activities or by using pattern practice which can be done by computer recording. Consider:

- John is reading a book.

- $\quad$ Mary.....................

(Instant feedback varies according to the situation e.g., I'm sorry, good answer, well done, excellent, try again, etc.)

10. Presenting authentic language e.g., listening to a native speaker, giving menus to the students, recordings of airport's announcements, news, etc.

11. Simulation of language use (e.g., acting, dramatization, etc.).

Clearly, educational aids can be used for different purposes. We can use them for teaching language skills and language components. In detail, educational aids can be used for teaching oral skills (listening and speaking) and written skills (reading and writing) and components of language (sound system, grammatical structures and vocabulary building). Psychoneurolinguists found them effective for teaching those who are suffering from permanent lassitude, logamnesia, logasthenia, logopathy, logoplegia, logorrhea and logospasm. In fact, they are also found useful for those who are suffering from macrogingivae, macroglossia, macrognathia, and macrolabia. Educational aids for teaching language skills and language components fall into five major types: Visual aids, audio aids, audio-visual aids, action (e.g., dramatization, field trips, debating, etc.), and multi-media (Computer-assisted language learning/ instruction/ teaching (CALL/I/T)). 
A: Visual aids: This type takes different forms and shapes:

1. Realia (Real things). This includes chalk, board, chair, etc.

2. Three dimensions models (e.g., trains).

3. Pictures or drawings: These can be photographic or hand drawn. There are different types of pictures:

- $\quad$ Simple pictures: Pictures of cars, pens, books, etc.

- Composite pictures: Pictures of scenes in classes, movies, etc.

- Series or sets: For example, telling stories, process of doing something (cooking, manufacturing, experiment, etc.), pictures of transportation means, etc.

4. Posters: Usually consists of picture and text (e.g., posters of "No Smoking").

5. Maps: These include geographical maps (used for topographical purposes), political maps, city plans, floor plans, etc. SLT can use city plan for example and ask the student who suffers from dyslexia to follow his instructions by drawing lines on the places he/ she is talking about.

6. Boards: There are many of them like smart boards, white boards, black boards, etc.

7. Cards: These include flash cards (where the picture is in one side and the word is in the other side), reading cards, and question \& answer cards, etc.

8. Graphs: One of the most famous graphs is the pie graphs. Pie graphs are normally used for statistical purposes.

9. Forms: To be used by students who are suffering from dysgraphia for example. Examples of forms: Immigration forms, customs forms, hotel forms, etc.

10. Menus: Restaurant menus that can be used to teach mentally handicapped students something about cultures, traditions, folklores, etc.

11. Slides: Overhead projectors (OHP) slides and $35 \mathrm{~mm}$ slides are some of the example for this type of visual aids. Many of the above mentioned visual aids can be converted into slide forms and then presented to the students of special needs to achieve some class activities.

12. Film strips: It is a set of slides like picture series. SLTs can also make use of silent films.

13. Comic books: Examples of this type are children books, stories, etc. that can be used to entertain children, notably those who have problems relating to dyscalculia. Such type also attracts the attention of students suffering from dysarthria and prompts them to speak.

14. Facial diagrams: Diagrams to be taken from books like phonological books or even by drawing them on the boards for teaching purposes like teaching articulation for those who are suffering from pronunciation problems. 
15. Clock, face, and hands: By asking the students to assign the time according to the question or vice versa. Such types of activities help dyscalculic students learn better.

16. Calendars: For counting days of the week, months of the year, numbers, etc. Again, such drill helps those who suffer from dyscalculia.

17. Letters of the alphabet and numbers: For teaching spelling, recognition of the letter, etc.

18. Cross-word puzzle: For teaching vocabularies. We also have scrabbles. Learning vocabulary items is very helpful for those who have developmental aphasia.

19. Tables \& schedules: These include time table, flight schedules, tec. Linking information to each other helps those who have global aphasia as it strengthens their abilities to speak and comprehend.

B: Audio-aids: Some audio aids that can be used for students who have language difficulties are:

1. Cassette recorder or radio: Such audio aid is typical, notably for those who have problems related to Wernicke's aphasia as it helps them comprehend what they are listening to. Those who suffer from conduction aphasia may benefit from these cassettes also as they have to repeat the words and / or phrases they are listening to. In others, they do not have to listen to themselves and repeat their own sentences more than one time.

2. Phonograph records: It is an old version of compact discs (CDs).

3. CDs.

4. Conversional language labs: In this kind of labs, one can have all the above mentioned audio aids.

C: Audio-visual aids: The most obvious types are T.V, videos, and also DVD which has almost the same function as the video tape. Sophisticated language lab is another audio-visual aid. In this kind of labs, students of special needs can have both recording and playing. They can also have the facility to speak and listen at the same time and then compare that. Another characteristic of these labs is the facility of instant repetition.

Sound movies are also some other types of audio-visual aids. These movies are now replaced by video tapes. Sound movies are the opposite of silent movies. SLTs can mute the sounds so that movies can be functioned for speaking or with the sound for listening. Slide/ sound synchronization is another type of audio-visual aids. In this type, students of special needs can have both sound and picture and this is used to be one of the methods used in the past and is called in French "La method audio-visuelle".

D: Action: This takes different shapes and forms:

1. Dramatization (physical action) like walking, standing up, etc. Such exercises are helpful for students suffering from Alalia. However, if the SLTs notices that his/ her student cannot act the action, then they can ask them (using sign language when necessary) to pantomime or imitate. 
2. Charade: Charade is a good exercise due to those students of special needs enjoy it so much. In this type of exercises, SLTs are supposed to play a role of something and their students predict what it is.

3. Party games: Many of them can be used be used as means for teaching language skills in general.

4. Language teaching games: They can be found in magazines, etc.

5. Field trips: They teach students of special needs some vocabularies. Students of special needs can also get practical experiences with them.

6. Role playing: It is a good example of actions.

7. Physical response: It is considered one of the ways of performing actions.

E: Multi-media aids (CALL/ CALT): They are combination of all the above mentioned aids including the use of internet, etc. Nor must we forget some general programs like T.V, radio, etc. SLTs should also pay attention to the use of computer as only one aspect of aids in language learning.

It is important, however, that SLTs know the best ways to use the above mentioned educative aids in teaching language to their students of special needs. As is seen in the earlier explanations, audio-visual aids and CALI can be used to teach those who are suffering from different motor and mental problems like megaloglossia (macroglossia), dysadaptation, dyschromatopsia/ dyschromasia (e.g., deuteranomaly, hemichromatopsia, hyperesophoria), encephalomyeloneuropathy, hemianencephaly, hyperthesia, etc. Some requirements for proper use of these educational aids (selection \& use) are as follows:

1- Aim (objective): In this regard, SLT should ask himself/ herself "Why am I using this aid in particular (a picture for instance)? Why not another/ other aid(s)?"

2- Effectiveness: Again, SLTs should ask themselves questions regarding to the effects (positive, negative, or side effects). Examples of these questions are: How effective is the use of this educative aid? What shall I do to make that educational aid more effective bearing in mind time, environment, students' levels, individual differences, types of language disorders, etc. For example, a documentary art subject will help students with dysmnesia remember things: Should I use it as a whole or just segment it in sections? When shall I use it? Shall I use it at the beginning, in the middle or at the end of the class?

3- Resources: Questions relating to the availability of the educational aids. These include: Where can I get the educative aid (s)? Are they available in toys' stores, bookstores, or internet?

4- Preparation: Making sure whether this educational aid is useable or not (usability of the educative aids and the best way (s) to use it.

Let's take an example of using these educational aids for teaching sound system. First, SLTs need to know what is meant by sound system. How is this audio-visual aid or CALI related to sound system? What kind of audio-visual aids and CALI should SLTs use when they teach 
students of special needs and which class of these students in particular should they target?

To answer all the above mentioned questions, SLTs should know that sound system includes segmental supra-segmental elements and factors, phonological process, combinations of phonemes like segments, etc. They also need to understand what they want to teach in sound system. They need discrimination drills and recognition exercises. A very common test is to say the word differently so that they can develop the suitable audio-visual aid and/ or CALI of distinguishing sounds. Discrimination means that SLT compares sounds with others. They need to recognize the sound when they are teaching articulation or pronunciations to students of special need, namely those who are suffering from dysprosody, dysphasia or paraphemia. To do so, they should bring list of pictures or vocabulary items and student of special needs compares the similarities and dissimilarities between these pictures and/ or vocabularies. Alternatively, SLTs can use imitation or repetition either by bringing a model or by asking students to listen. Production can also be used and it can be distinguished from repetition in the sense that in repetition, SLTs use models, while in in production, they do not. Notice here that discrimination is mentioned before production because students of special needs (especially those who are suffering from dyslalia) cannot produce the word unless they recognize it.

Again, one may ask here: What kind of audio-visual aids and CALI should SLTs use for teaching students of special needs the pronunciation? Psychoneurolinguistically, for teaching pronunciation to students of special needs in general, and those who are suffering from dysphemia, dysprosody, dysarthria, paraphemia, dysphasia, dyslalia or even those who are suffering from speech or voice disorders, SLTs can use the following audio-visual aids and CALI:

1. They can use realia or objects to give the meanings of the words that result from sound differences.

2. They can use action or facial diagrams.

3. They can also use films, mirrors, hand fingers, writing, etc.

4. They can use transcription for sounds that do not have letters like/ $\theta /, / \mathbf{b} /, / \mathfrak{t} /, / \mathrm{d}_{3} / / \mathrm{J} /$ and $13 /$.

5. They can have audio-visual aids and CALI like tape recorders, CDs, etc., for explaining pronunciations and meanings of words.

6. They can use hand, accent, capitalization, italics, underscoring, etc., to show stress and they can also use line drawn, etc., to show intonation. Consider:

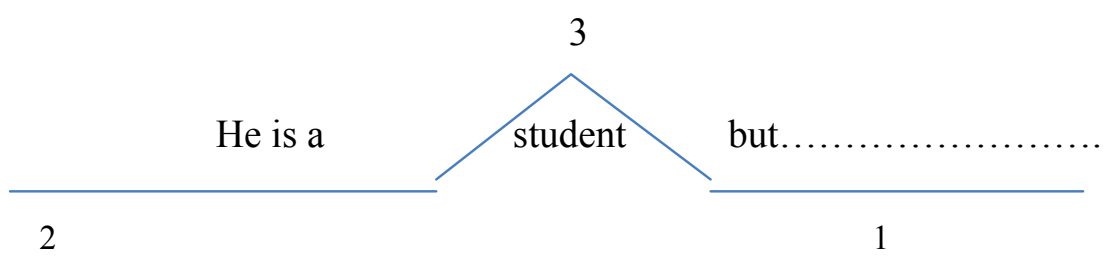


All the above mentioned audio-visual aids and CALI in addition to some other educative aids can be used as means to help students of special need see the contrast between the various distinctive features of sounds. Hence, it can be said that there are three phases for teaching sound system to students of special needs: Recognition, discrimination and repetition. Recognition as it has been explained earlier, means that when the student of special needs hears the sound, he/ she can easily recognize it. It requires knowledge of certain sounds. It is related to production like / $\theta /$ and $/ \sigma /$ in Egyptian or French accent of English for example which makes it difficult for students of special needs from these two countries. The same problem applies to Arab students of special needs when it comes to differentiate between sounds like $/ \mathrm{p} /$ and $/ \mathrm{b} /$ for example as the first does not exist in the Arabic sounds. A good visual aid for teaching recognition or discrimination is picture. Nor must we forget here to talk about facial diagram as a diagram that shows speech organs and which can be separated from animated films which are cartoon films (not real) films due to that one cannot see the unseen organs. Discrimination is used to distinguish one sound from another that is similar to it. Repetition as is seen earlier is to repeat the sound articulated by the SLT, and imitation is to imitate the way the sound is pronounced.

Computers can be involved in teaching sound system to students of special needs as follows:

1. Explanation of sound production like using facial diagrams, for example, with animation to indicate movement of tongue, etc.

2. Feedback on pronunciations like comparing the performance of students of special needs with master recording using speech recognition programs.

3. Providing exercises and drills for discrimination like minimal pairs with sound-same/ different, identifying certain sounds, etc.

4. Providing pictures with production exercises.

5. Providing model pronunciations to be imitated (repetition).

6. Speech recognition.

7. Speech synthesis (Oral instructions, pronunciation of words based on rules) $\times$ Speech recording (Pronunciation of words based on recording as can be seen in the electronic dictionaries).

8. Teaching intonation patterns.

9. Using / providing phonetic symbols (IPA).

Strictly, computers are found to be effective means for diagnosing those who are suffering from different physical and mental problems. These include those who are suffering from neuromyelitis, onomatophobia, pachyglossia, palatoplegia, palilalia, panotitis, paralalia, paralambdacism, paraphasia, paraphemia, paraphonia, paraphrasia, and mytacism.

\subsection{Audio-visual aids and CALI: Effects in the performance of students of special needs}

As is pointed out earlier in the methodology of this research, a total of 80 subjects from 8 to 
18 years old were evaluated. However, before undertaking the experiment, all subjects in both treatment and control groups were given a pre-test to be later compared with the posttest's outcomes. Raw scores are provided in Table 1. Considerer:

Table 1. Performance of the subjects in the pre-test: Comparison between the treatment and control groups

\begin{tabular}{|c|c|c|c|c|c|c|c|c|}
\hline \multirow[b]{2}{*}{ No } & \multicolumn{4}{|c|}{ Treatment/ Experimental group } & \multicolumn{4}{|c|}{ Control group } \\
\hline & Subject Name & 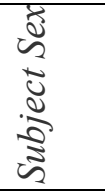 & $\begin{array}{l}\infty \\
\infty \\
\mathbb{U} \\
\tilde{D} \\
\tilde{\Xi} \\
\tilde{\Xi}\end{array}$ & 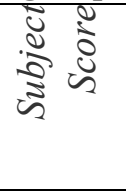 & $\begin{array}{r}\text { Subject } \\
\text { Name }\end{array}$ & 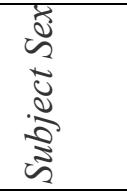 & 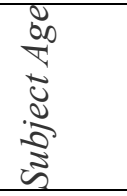 & 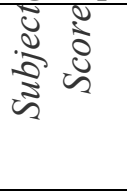 \\
\hline 1 & Saleh & M & 18 & 33 & Nada & $\mathrm{F}$ & 15 & 45 \\
\hline 2 & Majed & M & 12 & 23 & Hajar & $\mathrm{F}$ & 14 & 29 \\
\hline 3 & Saqr & M & 14 & 14 & Hamas & $\mathrm{F}$ & 8 & 15 \\
\hline 4 & Ali & $\mathrm{M}$ & 8 & 18 & Rashad & $\mathrm{M}$ & 12 & 29 \\
\hline 5 & Amatallateef & $\mathrm{F}$ & 12 & 44 & Omar & $\mathrm{M}$ & 9 & 16 \\
\hline 6 & Amatala'leem & $\mathrm{F}$ & 9 & 40 & Ashraf & M & 16 & 17 \\
\hline 7 & Badr & $\mathrm{M}$ & 13 & 18 & Mohammad & $\mathrm{M}$ & 11 & 32 \\
\hline 8 & Tareq & M & 14 & 29 & Montaha & $\mathrm{F}$ & 14 & 36 \\
\hline 9 & Parees & $\mathrm{F}$ & 15 & 26 & Ayman & M & 13 & 27 \\
\hline 10 & Bayrout & $\mathrm{F}$ & 9 & 39 & Aayah & $\mathrm{F}$ & 10 & 27 \\
\hline 11 & Tammaah & M & 9 & 23 & Adham & $\mathrm{M}$ & 10 & 11 \\
\hline 12 & Taher & $\mathrm{M}$ & 17 & 43 & Nasser & $\mathrm{M}$ & 11 & 12 \\
\hline 13 & Baraah & $\mathrm{F}$ & 16 & 18 & Haylah & $\mathrm{F}$ & 17 & 15 \\
\hline 14 & Abrar & $\mathrm{F}$ & 11 & 39 & Tawfeeq & M & 13 & 37 \\
\hline 15 & Ahmad & M & 13 & 27 & Nour & $\mathrm{F}$ & 12 & 20 \\
\hline 16 & Fatimah & $\mathrm{F}$ & 16 & 19 & Najeebah & $\mathrm{F}$ & 18 & 33 \\
\hline 17 & Amatillah & $\mathrm{F}$ & 18 & 9 & Radha'a & $\mathrm{F}$ & 16 & 35 \\
\hline 18 & Abdullateef & M & 8 & 25 & Wafa'a & $\mathrm{F}$ & 15 & 39 \\
\hline 19 & Amriyah & $\mathrm{F}$ & 12 & 32 & Wajedah & $\mathrm{F}$ & 15 & 37 \\
\hline 20 & Abduljaleel & M & 12 & 45 & Sultan & M & 9 & 29 \\
\hline 21 & Kareemah & $\mathrm{F}$ & 11 & 54 & A'simah & $\mathrm{F}$ & 12 & 28 \\
\hline 22 & Nadiyah & $\mathrm{F}$ & 11 & 12 & Adalah & $\mathrm{F}$ & 11 & 17 \\
\hline 23 & Sariyah & $\mathrm{F}$ & 13 & 16 & Abulwali & M & 8 & 36 \\
\hline 24 & Sarah & $\mathrm{F}$ & 13 & 18 & A'amal & $\mathrm{F}$ & 8 & 39 \\
\hline 25 & Huda & $\mathrm{F}$ & 18 & 12 & Salah & $\mathrm{M}$ & 12 & 27 \\
\hline 26 & Sulayman & M & 15 & 38 & Ammar & M & 13 & 47 \\
\hline 27 & Amjad & M & 14 & 33 & Luluah & $\mathrm{F}$ & 18 & 39 \\
\hline 28 & Abdullah & M & 11 & 26 & Bilal & M & 14 & 26 \\
\hline 29 & Abdulmajeed & M & 16 & 23 & Ziad & M & 12 & 19 \\
\hline 30 & Raghad & $\mathrm{F}$ & 15 & 26 & Ruqayah & $\mathrm{F}$ & 18 & 20 \\
\hline 31 & Hafsah & $\mathrm{F}$ & 14 & 28 & Asma'a & $\mathrm{F}$ & 15 & 19 \\
\hline 32 & Abdurrahman & $\mathrm{M}$ & 14 & 29 & Sumayah & $\mathrm{F}$ & 17 & 36 \\
\hline
\end{tabular}




\begin{tabular}{|c|c|c|c|c|c|c|c|c|}
\hline 33 & Akram & $\mathrm{M}$ & 14 & 37 & Kawthar & $\mathrm{F}$ & 13 & 38 \\
\hline 34 & Taqwa & $\mathrm{F}$ & 13 & 13 & Khawlah & $\mathrm{F}$ & 14 & 28 \\
\hline 35 & Salma & $\mathrm{F}$ & 12 & 15 & Tasneem & $\mathrm{F}$ & 18 & 24 \\
\hline 36 & Hadiyah & $\mathrm{F}$ & 18 & 19 & Amal & $\mathrm{F}$ & 10 & 28 \\
\hline 37 & Sayda & $\mathrm{F}$ & 18 & 27 & Sami & $\mathrm{M}$ & 10 & 18 \\
\hline 38 & Abdulkareem & $\mathrm{M}$ & 16 & 17 & Haneen & $\mathrm{F}$ & 10 & 16 \\
\hline 39 & Sadeq & M & 8 & 28 & Ayham & M & 16 & 6 \\
\hline 40 & Motaz & $\mathrm{M}$ & 10 & 38 & Sajidah & $\mathrm{F}$ & 18 & 44 \\
\hline $\begin{array}{l}\stackrel{\pi}{0} \\
\qquad\end{array}$ & $40(20 \mathrm{M}+20 \mathrm{~F})$ & & 530 & 1073 & \multicolumn{2}{|c|}{$40(20 \mathrm{M}+20 \mathrm{~F})$} & 525 & 1096 \\
\hline 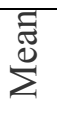 & & -- & 13.25 & $26.82 \%$ & & - & 13.12 & $27.4 \%$ \\
\hline
\end{tabular}

Research on the effects of using new treatment tool in the psychoneurolinguistic field has consistently increased since the advent of audio-visual aids and CALI. The evidence from therapy-induced aphasia recovery studies shows that better recovery in the performance levels of students of special needs results from the abundant use of these educational aids, notably for teaching language components including sound system which they need most. Still, the specific key areas that sign successful outcome with a specific educative approach remain to be identified. Obviously, Table 2 shows that the performance of the two groups (treatment and control groups) is similar (26.82\% vs. $27.4 \%)$.

As is known in experimental studies of the same nature, pre-tests' scores remain valueless unless they are compared to those of the posttests. However, it is a good thing to understand them as a base for what results follow. In this regard, that the validity of the current study has been ensured, especially when looking at the scores of both treatment and control groups (Males $=567$ and 389 and females $=506$ and 707). These results can better be understood in view of the outcomes of posttest in Table 2.

Consider:

Table 2. Performance of the subjects in the post-test: Comparison between the treatment and control groups

\begin{tabular}{|c|c|c|c|c|c|c|c|c|}
\hline \multirow[b]{2}{*}{ No } & \multicolumn{4}{|c|}{ Treatment/ Experimental group } & \multicolumn{4}{|c|}{ Control group } \\
\hline & Subject Name & 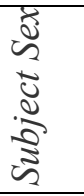 & 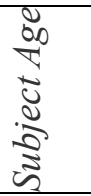 & 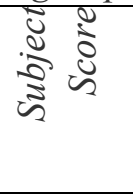 & $\begin{array}{r}\text { Subject } \\
\text { Name }\end{array}$ & 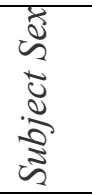 & 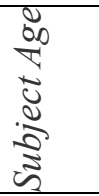 & 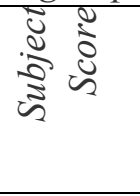 \\
\hline 1 & Saleh & $\mathrm{M}$ & 18 & 78 & Nada & $\mathrm{F}$ & 15 & 27 \\
\hline 2 & Majed & $\mathrm{M}$ & 12 & 68 & Hajar & $\mathrm{F}$ & 14 & 13 \\
\hline 3 & Saqr & $\mathrm{M}$ & 14 & 69 & Hamas & $\mathrm{F}$ & 8 & 46 \\
\hline
\end{tabular}




\section{MInstitute ${ }^{\text {Mach }}$}

Journal for the Study of English Linguistics

ISSN 2329-7034

2013, Vol. 1, No. 2

\begin{tabular}{|c|c|c|c|c|c|c|c|c|}
\hline 4 & Ali & $\mathrm{M}$ & 8 & 98 & Rashad & $\mathrm{M}$ & 12 & 29 \\
\hline 5 & Amatallateef & $\mathrm{F}$ & 12 & 78 & Omar & $\mathrm{M}$ & 9 & 30 \\
\hline 6 & Amatala'leem & $\mathrm{F}$ & 9 & 67 & Ashraf & M & 16 & 37 \\
\hline 7 & Badr & $\mathrm{M}$ & 13 & 64 & Mohammad & M & 11 & 49 \\
\hline 8 & Tareq & $\mathrm{M}$ & 14 & 56 & Montaha & $\mathrm{F}$ & 14 & 36 \\
\hline 9 & Parees & $\mathrm{F}$ & 15 & 49 & Ayman & $\mathrm{M}$ & 13 & 59 \\
\hline 10 & Bayrout & $\mathrm{F}$ & 9 & 90 & Aayah & $\mathrm{F}$ & 10 & 29 \\
\hline 11 & Tammaah & $\mathrm{M}$ & 9 & 98 & Adham & $\mathrm{M}$ & 10 & 17 \\
\hline 12 & Taher & $\mathrm{M}$ & 17 & 79 & Nasser & $\mathrm{M}$ & 11 & 27 \\
\hline 13 & Baraah & $\mathrm{F}$ & 16 & 56 & Haylah & $\mathrm{F}$ & 17 & 15 \\
\hline 14 & Abrar & $\mathrm{F}$ & 11 & 79 & Tawfeeq & M & 13 & 25 \\
\hline 15 & Ahmad & $\mathrm{M}$ & 13 & 56 & Nour & $\mathrm{F}$ & 12 & 34 \\
\hline 16 & Fatimah & $\mathrm{F}$ & 16 & 49 & Najeebah & F & 18 & 18 \\
\hline 17 & Amatillah & $\mathrm{F}$ & 18 & 96 & Radha'a & $\mathrm{F}$ & 16 & 16 \\
\hline 18 & Abdullateef & $\mathrm{M}$ & 8 & 58 & Wafa'a & $\mathrm{F}$ & 15 & 24 \\
\hline 19 & Amriyah & $\mathrm{F}$ & 12 & 70 & Wajedah & $\mathrm{F}$ & 15 & 8 \\
\hline 20 & Abduljaleel & $\mathrm{M}$ & 12 & 84 & Sultan & $\mathrm{M}$ & 9 & 26 \\
\hline 21 & Kareemah & $\mathrm{F}$ & 11 & 56 & A'simah & $\mathrm{F}$ & 12 & 13 \\
\hline 22 & Nadiyah & $\mathrm{F}$ & 11 & 68 & Adalah & $\mathrm{F}$ & 11 & 45 \\
\hline 23 & Sariyah & $\mathrm{F}$ & 13 & 98 & Abulwali & M & 8 & 34 \\
\hline 24 & Sarah & $\mathrm{F}$ & 13 & 79 & A'amal & $\mathrm{F}$ & 8 & 38 \\
\hline 25 & Huda & $\mathrm{F}$ & 18 & 70 & Salah & M & 12 & 27 \\
\hline 26 & Sulayman & $\mathrm{M}$ & 15 & 90 & Ammar & $\mathrm{M}$ & 13 & 47 \\
\hline 27 & Amjad & $\mathrm{M}$ & 14 & 78 & Luluah & $\mathrm{F}$ & 18 & 49 \\
\hline 28 & Abdullah & $\mathrm{M}$ & 11 & 87 & Bilal & $\mathrm{M}$ & 14 & 44 \\
\hline 29 & Abdulmajeed & $\mathrm{M}$ & 16 & 67 & Ziad & $\mathrm{M}$ & 12 & 39 \\
\hline 30 & Raghad & $\mathrm{F}$ & 15 & 34 & Ruqayah & $\mathrm{F}$ & 18 & 19 \\
\hline 31 & Hafsah & $\mathrm{F}$ & 14 & 56 & Asma'a & $\mathrm{F}$ & 15 & 27 \\
\hline 32 & Abdurrahman & $\mathrm{M}$ & 14 & 78 & Sumayah & $\mathrm{F}$ & 17 & 24 \\
\hline 33 & Akram & $\mathrm{M}$ & 14 & 87 & Kawthar & $\mathrm{F}$ & 13 & 35 \\
\hline 34 & Taqwa & $\mathrm{F}$ & 13 & 57 & Khawlah & $\mathrm{F}$ & 14 & 39 \\
\hline 35 & Salma & $\mathrm{F}$ & 12 & 89 & Tasneem & $\mathrm{F}$ & 18 & 37 \\
\hline 36 & Hadiyah & $\mathrm{F}$ & 18 & 90 & Amal & $\mathrm{F}$ & 10 & 39 \\
\hline 37 & Sayda & $\mathrm{F}$ & 18 & 90 & Sami & $\mathrm{M}$ & 10 & 37 \\
\hline 38 & Abdulkareem & $\mathrm{M}$ & 16 & 45 & Haneen & $\mathrm{F}$ & 10 & 25 \\
\hline 39 & Sadeq & $\mathrm{M}$ & 8 & 56 & Ayham & $\mathrm{M}$ & 16 & 23 \\
\hline 40 & Motaz & $\mathrm{M}$ & 10 & 76 & Sajidah & $\mathrm{F}$ & 18 & 34 \\
\hline $\begin{array}{l}\bar{\pi} \\
\text { है } \\
\qquad\end{array}$ & $40(20 \mathrm{M}+20 \mathrm{~F})$ & & 530 & 2893 & \multicolumn{2}{|c|}{$40(20 \mathrm{M}+20 \mathrm{~F})$} & 525 & 1240 \\
\hline
\end{tabular}




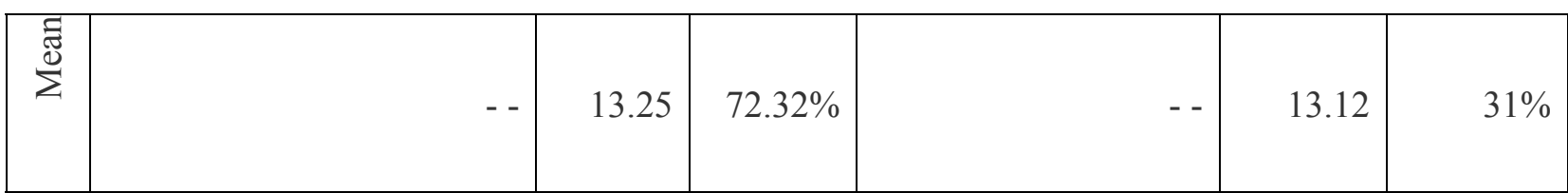

The effects of using audio-visual aids and CALI as a new treatment on the level of students of special needs studying sound system were compared in pee-and-posttests. Table 2 summarizes the results of the eighty subjects selected for this study. Unlike their friends in the control group, the subjects in the experimental group used audio-visual aids and CALI to study sound system. Training included all audio-visual means and CALI that can be even used as treatment strategies to elicit proper pronunciations and perfect articulation of target sounds, words, phrases and clauses. Treatment effects were measured using SPSS. A quick look at the results of the subjects in the two groups reveal significant improvement in the performance of the treatment group compared with the control group (72.32\% vs. $31 \%)$. Such improvement did not exist between the same groups in the pre-test (26.82\% vs. 27.4).

In comparison to the scores of the females (1421), the males' scores are higher (1472). Looking at the scores of the two control groups of both males and females in both pre-and-posttests (Pre-test $=389$ and 707 vs. posttest $=550$ and 690), one can realize how validity is ensured. All in all, posttests' score the most significant ones and figure 2 concludes them. Compare:

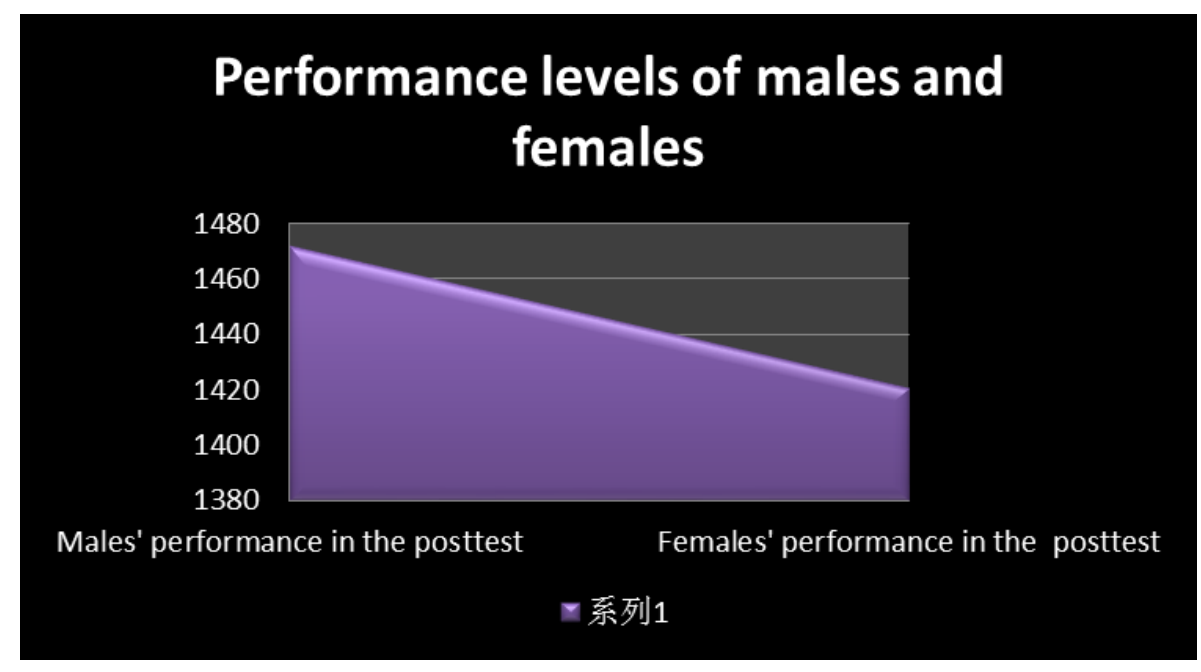

Figure 2. Performance levels of males and females in posttest: Comparison.

These comparisons provide preliminary data supporting the guarantee benefits of utilizing audio-visual aids and CALI not only as means for helping them study sound systems and its distinctive features, but also as a treatment tool in the recovery of students of special needs

\section{Conclusions \& Recommendations}

Aids to language teaching are of three broad categories: Conventional aids, technological aids (machines other than computer) and CALL. There are some techniques that can be effectively 
used for teaching language in general. These strategies can be used for teaching nearly all language aspects including the sound system, grammatical structures and vocabulary (language components) as well as teaching the four language skills and culture. Generally, educative aids are of three types. The first type includes visual aids: (e.g., realia, models, pictures/ drawings, posters, maps (geographic and city plans), boards, cards (flash cards, reading cards- Questions \& Answers), graphs, forms, menus, slides (35 mm and OHP), film strips, silent films, comic books and strips, facial diagrams, clock faces and hands, calendars, charts, letters of the alphabet and numbers, cross-word puzzles, etc.). The second type is related to audio aids (including lab) (e.g., audio cassette/ tape (reel) recorders, radio, phonograph records (record albums), CDs, conventional labs. The third type is that of audio-visual aids (e.g., video tapes, TV, digital versatile disc (DVD), sound films, synchronized audio recording with visual presentations (slides), action aids (e.g., dramatization, field trips, games, pantomime, etc. ) and multimedia (e.g., CALT/ L), the use of internet, interactive or not, etc.).

A very legitimate question here is: What is the importance of educative aids (Audio-visual aids and CALI) in speech language pathology? To answer such question, SLTs need to know the characteristics and benefits of audio-visual aids and CALI. Some of these features are relating to attracting attention, maintaining attention. Some SLTs emphasize that audio- visual aids and CALI can be used in matters relating to the clarification of concepts/ meanings of words and utterances. According to these SLTs, these educative aids participate in increasing the chances of remembrance by increasing means of association, saving time, simulation of language use, and presenting authentic language and natural settings for language use. Others add that audio-visual aids and CALI can be exploited to compensate for lack of experience of teachers, individualize learning and instruction, involve of learners, give variety to the lesson, and provide instant feedback.

Computers in general and computer programs in particular were found to be successful in achieving transfer of trained language abilities in speed of processing to similar untrained tasks. They can be used as means of presentation of text and also as means of presentation of exercises and feedback (and/or evaluation). Moreover, one can implement them for other educational purposes where they can be effectively used as sources of texts and also as a means of providing a record of students' progress. In addition, computers are the best educative environments where one can easily find all types of electronic dictionaries (e.g., Thesauri, Sakhr, Atlas, Longman, Contemporary, Webster, etc.). Other available electronic references include grammatical/ usage information, information sources (encyclopedia, etc.), and internet access where communication takes place with others. Strictly, internet facilities found to be useful for teaching, references, consultation, interaction with others, practicing through chatting, learning individually or through collaboration (on assignments, etc.).

CALI requires some procedures to be undertaken before therapeutic sessions take place. Standing alone is the first procedure and this refers to two important points: Considering class complementary work, and language course (autonomous learning). Network is another procedure that SLTs should pay attention to. They should make sure that all necessary networks (e.g., local area network), internet access, supplementary materials, language course 
(Autonomous learning), etc., are available. Nor must we forget to add also the feature of benefiting from computer mediated communications (CMC) (e.g., e-mail, chat, distant learning), information tools ( different topics, language aids like dictionaries, and/ or using computer as a tool (word processing, spell checkers, grammar checker, word count).

Programmed instruction (self-teaching/ learning) can be used to break learning task/ information into small bits, present these in frames which require response by the learner and then provide feedback by the system. In fact, a connection ought to be made between the uses of programmed instruction and CALI since the former is a part of the latter. Such uses of the programmed instruction require us to mention something about the advantages of CALI. These include: Individualization, instant feedback, combining efforts of different experts, assessment, follow-up learner's progress, providing diagnostic report on learners, provision of authentic materials, use of multimedia, combination of different resources (lexical, grammatical, cultural...) and use of corpus linguistic facilities (such as concordancers- key word in context (KWIC)).

Before discussing audio-visual aids and CALI that are recommended for teaching the sound system, SLTs should be familiar with two characteristics that accompany sounds systems. These are:

1- Discrimination/ recognition of sound system (Differences between characteristic features of sound like minimal pairs e.g., pin, pen).

2- Production of sound system (imitation and repetition, reading aloud and free production).

From among the audio-visual aids and CALI that can be used for teaching sound system, one can find tape recorders; records, CDs, language laboratory, radio and these are considered audio aids. Regarding the visual aids that are recommended for teaching sound system to students of special needs, one cannot neglect facial diagrams, line drawings (for intonation contour) films for explanation of production of sounds (actual or animated), phonetic transcription, mirrors, hand figures, realia, pictures, written text, etc. For the audio-visual aids, hearing pronouns, seeing the words/ utterance and accompanying pictures are some of the aids recommended. Nor must we forget the multimedia which includes TV, internet, movie theaters, etc. In order to recommend the suitable audio-visual aids and CALI for teaching sound system including teaching pronunciation / sound system, SLPTs should consider the appropriateness of using the aids, especially when it comes to issues relating sounds' representation. The following guidelines ought to be taken into consideration:

- Conventional spelling/ letters OR phonetic transcription. SLT is strongly recommended to download symbols from the internet.

- Pictures and drawings and realia are also recommended to show the meanings of contrasting words.

- Sounds should be presented (audio presentation).

- Facial diagrams are also recommended with or without animation to explain the articulation of sounds. 
- SLTs should tackle comparisons and instant feedback on the learner's performance (Speech recognition facility is required for segmental).

- Line drawings are necessary to indicate intonation patterns and the same thing applies to fonts, colors, and other means to show place of stress (stressed syllables).

- SLTs should Provide exercises for discrimination (e.g., minimal pairs with sound- Same/ Different, Identify certain sounds).

- SLTs are also expected to provide their students of special needs with more explanations of sound production (e.g., using facial diagrams with animation to indicate movement of tongue).

- $\quad$ SLTs should use/ provide phonetic symbols from internet or any other reference (IPA).

- $\quad$ SLTs should provide model pronunciation to be imitated (repetition).

- $\quad$ SLTs should provide pictures with production exercises.

- Feedback is necessary on pronunciation (comparing student's performance with master recording - using speech recognition).

Using audio-visual aids and CALI for teaching sound system to students of special needs resulted in effects on the verbal productions of the subjects under investigation. In particular, these educative aids resulted in improved the sound system as a language components in 40 subjects (treatment group). Such improvement covered not only the sound system; rather, related-phonetic and phonological characteristics (e.g., phonemes, morphemes, segmental; and supra-segmental elements, allophones, stems, roots, etc.) are also included. Figure 1 illustrates the performance development of both treatment and control groups in both pre-and-posttests. Compare:

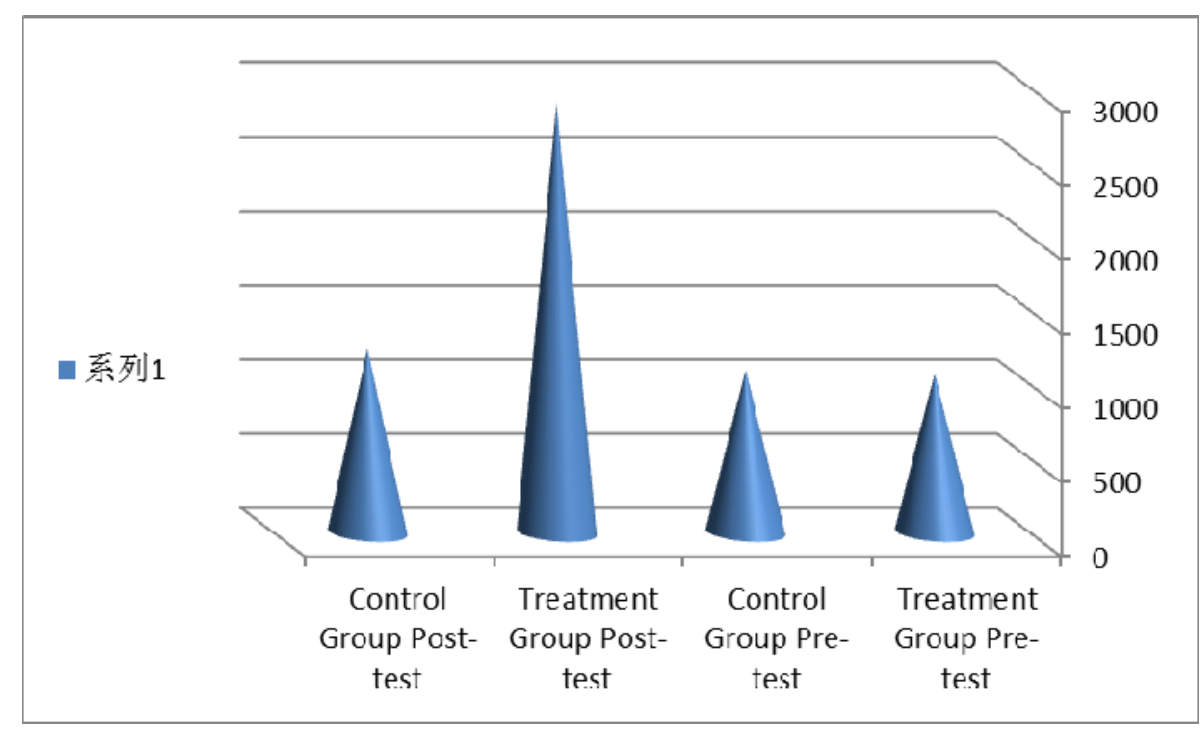

Figure 1. Results of the treatment and control groups' pre-and-posttests: Comparison 
Clearly, the subjects of the treatment received immediate effects on their performance levels in comparison to their competitors in the control group. Improvements on the performance levels were evident in the posttest. Figure 1 illustrates these improvements. While the two groups achieved nearly similar level if not the same (between 500-1000 scores), the control group in the posttest scored higher marks $(<1000)$. Such results revealed that audio-visual aids and CALI had positive educative and treatment effects on the performance levels of students of special needs, notably in matters concerning language components in general and sound system in particular. They also confirmed those of other studies undertaken on the same issue (Gilakjani, 2012; Peressotti \& Colombo, 2012; Augustinova \& Ferrand, 2012; Pike, 2012; Swimelar, 2013; Wild, 2013; Pérez-Bellido, et al., 2013; and SuHua, et al., 2013).

\section{Acknowledgement}

Thanks a lot to Prof. Kebbe for his patience and steadfast encouragement to complete this study;

\section{References}

Ahmed, S. S. (2012). Media pedagogy - the medium is the message. Paper presented at the (64), 425-430. Retrieved from http://search.proquest.com/docview/1220675367?accountid=44936.

Álvarez, G. (2012). New technologies in the university context: The use of blogs for developing students' reading and writing skills. RUSC, 9(2), 185-198. Retrieved from http://search.proquest.com/docview/1030155853?accountid=44936.

Anson, C. M., \& Schwegler, R. A. (2012). Tracking the mind's eye: A new technology for researching twenty-first-century writing and reading processes. College Composition and Communication, 64(1), 151-171. Retrieved from http://search.proquest.com/docview/1081830986?accountid=44936.

Augustinova, M., \& Ferrand, L. (2012). Suggestion does not de-automatize word reading: Evidence from the semantically based stroop task. Psychonomic Bulletin \& Review, 19(3), 521-527. Retrieved from http://search.proquest.com/docview/1020164947?accountid=44936. http://dx.doi.org/10.3758/s13423-012-0217-y.

Bradham, S. T. (2012). From the ear to the brain: Advances in understanding auditory function, technology and spoken language development. The Volta Review, 112(2), 149-180. Retrieved from http://search.proquest.com/docview/1095617934?accountid=44936.

Brown, A., Stevens, R., \& Pettifer, S. (2013). Making Graph-Based Diagrams Work in Sound: The Role of Annotation. Human-Computer Interaction, 28(3), 193-221. http://dx.doi.org/10.1080/07370024.2012.697010.

Chen, I., \& Yen, J. (2013). Hypertext annotation: Effects of presentation formats and learner proficiency on reading comprehension and vocabulary learning in foreign languages. Computers \& Education, 63, 416-423. http://dx.doi.org/10.1016/j.compedu.2013.01.005.

Damoiseaux, J., Mallet, K., Vaessen, M., Austen, J., \& Jan-Willem, C. T. (2012). Automatic 
reading of ANCA-slides: Evaluation of the AKLIDES system. Clinical \& Developmental Immunology, 762874. http://dx.doi.org/10.1155/2012/762874.

Davies, G., \& Higgins, A. (1992). Language and Language Learning. London: CILT.

Devimeenakshi, K., \& Maheswari, C. N. (2012). Using original methods in teaching english language to foreign students (chinese) in indian classroom. English Language Teaching, 5(9), 166-177. Retrieved from http://search.proquest.com/docview/1039540643?accountid=44936. http://dx.doi.org/10.5539/elt.v5n9p166.

Diaz-Maurin, F., \& Giampietro, M. (2013). A "Grammar" for assessing the performance of power-supply systems: Comparing nuclear energy to fossil energy. Energy, 49, 162-177.

Fuenzalida, V., \& Sjöberg, U. (2012). The cultural opportunity of children's television public policies in digital Television/A response to "the cultural opportunity of children's TV: Public policies in digital television". Communication Research Trends, 31 (3), 4-22. Retrieved from http://search.proquest.com/docview/1112924145? accountid=44936.

Gessesse, C., \& Sileshi, L. (2013). The Semiotics of HIV/AIDS Bill-Boards and Their Communication Implications: The Case of Bahir Dar and Gondar Towns in Ethiopia. Online Journal Of Communication \& Media Technologies, 3(1), 240-275.

Gilakjani, A. P. (2012). A study on the impact of using multimedia to improve the quality of english language teaching. Journal of Language Teaching and Research, 3(6), 1208-1215. Retrieved from http://search.proquest.com/docview/1272283949?accountid=44936. http://dx.doi.org/10.4304/jltr.3.6.1208-1215.

Gower, L., \& McDowall, J. (2012). Interactive music video games and children's musical development. British Journal of Music Education, 29(1), 91-105. http://dx.doi.org/10.1017/S0265051711000398.

Harcourt, B., \& Templer, B. (2005). "Towards a People's English: Back to BASIC in EIL”. Humanising Language Teaching, 1-5.

Henderson, J. M., \& Luke, S. G. (2012). Oculomotor inhibition of return in normal and mindless reading. Psychonomic Bulletin \& Review, 19(6), 1101-1107. Retrieved from $\mathrm{http}: / /$ search.proquest.com/docview/1268714917? accountid=44936.

http://dx.doi.org/10.3758/s13423-012-0274-2.

Iram, S. (2012). Reading needs, facilities and problems of visually impaired people. Pakistan Journal of Library and Information Science, (13), 1-H1. Retrieved from http://search.proquest.com/docview/1242449874?accountid=44936. Available at http://pu.edu.pk/home/journal/8. ISSN 1680-4465.

Ismail, A. S., Hamed, M. A., \& Abdurrahman, G. A. (2012). Employing reading and writing computer-based instruction in english as a second language in elementary schools. International Journal of Business and Social Science, 3(12), 3-4. Retrieved from $\mathrm{http}: / /$ search.proquest.com/docview/1022655978? accountid=44936. 
Khaliq, M. F., Noorani, M. M., Siddiqui, U. A., \& Anwar, M. (2012). Physicians reading and writing practices: A cross-sectional study from civil hospital, karachi, pakistan. BMC Medical Informatics and Decision Making, 12(1), 76. http://dx.doi.org/10.1186/1472-6947-12-76. http://www.biomedcentral.com/1472-6947/12/76.

Kirk, K. I., Prusick, L., French, B., Gotch, C., Eisenberg, L. S., \& Young, N. (2012). Assessing spoken word recognition in children who are deaf or hard of hearing: A translational approach. Journal of the American Academy of Audiology, 23(6), 464-75. Retrieved from http://search.proquest.com/docview/1022698261 ?accountid=44936. http://dx.doi.org/10.3766/jaaa.23.6.8.

Klingenberg, O. G. (2012). Conceptual understanding of shape and space by braille-reading norwegian students in elementary school. Journal of Visual Impairment \& Blindness, 106(8), 453-465. Retrieved from http://search.proquest.com/docview/1034974451 ?accountid=44936.

Levesque, R. (2007). SPSS Programming and Data Management: A Guide for SPSS and SAS Users, Fourth Edition. SPSS Inc., Chicago Ill. PDF, 1-3. ISBN 1-56827-390-8.

Levy, M. (1997). CALL: context and conceptualisation. Oxford: Oxford University Press.

Liu, X., Hieronymus, J. L., Gales, M. F., \& Woodland, P. C. (2013). Syllable language models for Mandarin speech recognition: Exploiting character language models. Journal of The Acoustical Society Of America, 133(1), 519-528. http://dx.doi.org/10.1121/1.4768800.

Macleod, A., Fabiano-Smith, L., Boegner-Pagé, S., \& Sami Fontolliet, S. (2013). Simultaneous bilingual language acquisition: The role of parental input on receptive vocabulary development. Child Language Teaching \& Therapy, 29(1), 131-142. http://dx.doi.org/10.1177/0265659012466862.

Manoli, P., \& Papadopoulou, M. (2012). Graphic organizers as a reading strategy: Research findings and issues. Creative Education, 3(3), 348-356. Retrieved from http://search.proquest.com/docview/1022986447?accountid=44936.

http://dx.doi.org/10.4236/ce.2012.33055.

Mead, A. R., Bradwell, R. P., \& Stokes, G. P. (1999). Advanced atlas of autoantibody patterns. Birmingham: The Binding Site. ISBN 0704485109.

Onnis, L., \& Thiessen, E. (2013). Language experience changes subsequent learning. Cognition, 126(2), 268-284. http://dx.doi.org/10.1016/j.cognition.2012.10.008.

Pavan, A., \& Baggio, G. (2013). Linguistic Representations of Motion Do Not Depend on the Visual Motion System. Psychological Science (Sage Publications Inc.), 24(2), 181-188. http://dx.doi.org/10.1177/0956797612450882.

Peek, H. B. (2010). "The Emergence of the Compact Disc". IEEE Communications Magazine 48 (1), 10-17. http://dx.doi.org/10.1109/MCOM.2010.5394021.ISSN 0163-6804.

Peinhardt, R. D., \& Hagler, D. (2012). Peer coaching to support writing development. Journal of Nursing Education, $\quad$ 52(1), 
http://dx.doi.org/10.3928/01484834-20121121-02.

Perea, M. (2012). Revisiting huey: On the importance of the upper part of words during reading. Psychonomic Bulletin \& Review, 19(6), 1148-1153. Retrieved from http://search.proquest.com/docview/1268714918?accountid=44936.

http://dx.doi.org/10.3758/s13423-012-0304-0.

Peressotti, F., \& Colombo, L. (2012). Reading aloud pseudohomophones in italian: Always an advantage. Memory \& Cognition, 40(3), 467-482. Retrieved from http://search.proquest.com/docview/953523238?accountid=44936.

http://dx.doi.org/10.3758/s13421-011-0161-5.

Pérez-Bellido, A., Soto-Faraco, S., \& López-Moliner, J. (2013). Sound-driven enhancement of vision: disentangling detection-level from decision-level contributions. Journal Of Neurophysiology, 109(4), 1065-1077.

Pike, P. D. (2012). Sight-Reading Strategiews: For the beginning and intermediate piano student A fresh look at A familiar topic. The American Music Teacher, 61(4), 23-28,3. Retrieved from http://search.proquest.com/docview/922376823?accountid=44936.

Su, S., \& Liu, C. (2012). Teaching listening comprehension skills: A test-orientated approach. Journal of Language Teaching and Research, 3(3), 458-465. Retrieved from http://search.proquest.com/docview/1019434925?accountid=44936.

http://dx.doi.org/10.4304/jltr.3.3.458-465.

SuHua, H., Clark, N., \& Wedel, W. (2013). Teaching Tips: The Use of an iPad to Promote Preschoolers' Alphabet Recognition and Letter Sound Correspondence. Practically Primary, 18(1), 24-26.

Swimelar, S. (2013). Visualizing International Relations: Assessing Student Learning Through Film. International Studies Perspectives, 14(1), 14-38. http://dx.doi.org/10.1111/j.1528-3585.2012.00467.x.

Taft, M., \& Krebs-Lazendic, L. (2013). The role of orthographic syllable structure in assigning letters to their position in visual word recognition. Journal Of Memory \& Language, 68(2), 85-97. http://dx.doi.org/10.1016/j.jml.2012.10.004.

Thrasher, A. (1996). "DVD: coming soon to your PC?". Computer Shopper 16 (3), 189.

Wild, T. A., Hilson, M. P., \& Hobson, S. M. (2013). The Conceptual Understanding of Sound by Students with Visual Impairments. Journal Of Visual Impairment \& Blindness, 107(2), 107-116.

Wolf, M., Ullman-Shade, C., \& Gottwald, S. (2012). The emerging, evolving reading brain in a digital culture: Implications for new readers, children with reading difficulties, and children without schools. Journal of Cognitive Education and Psychology, 11(3), 230-240. Retrieved from http://search.proquest.com/docview/1124437587?accountid=44936. 


\section{Glossary}

ANCA (Anti-neutrophil cytoplasmic antibodies) = These are a group of autoantibodies and monocytes that are detected as a blood test in a number of autoimmune disorders, but are particularly associated with systemic vasculitis. ANCA often "show combinations of both cytoplasmic and perinuclear staining." (Mead, et al., 1999: p.1).

CALL/I/T (Computer-assisted/aided language learning/instruction/teaching) = It is defined as "the search for and study of applications of the computer in language, teaching and learning." (Levy, 1997: p.1). While CALL is related to students, CALT and CALI "fell out of favor among teachers". In that sense, it can be said that while in the former term, the student-centered approach is the dominant perspective, in the latter; a teacher-centered approach is more preferred. CALI/T exhibits all characteristics of English language teaching (ELT) (Davies G. \& Higgins, 1992: p.3).

CD $($ Compact Disc $)=$ It is used for storage of data. It was in March 1974, during a meeting of the audio group, two engineers from the Philips research laboratory recommended the use of a digital format on the $20 \mathrm{~cm}$ optical disc, because an error-correcting code could be added." (Peek, 2010: p. 10).

CMC (Computer-mediated communication) $=$ According to McQuail (2005), CMC is seen as "any communication that occurs through the use of two or more electronic devices." (McQuail, 2005: p.1)

DVD (Digital versatile disc) $=$ It is a digital optical disc storage format. The DVD specification provided a storage capacity of $4.7 \mathrm{~GB}$ for a single-layered, single-sided disc and 8.5 GB for a "dual-layered, single-sided disc." (Thrasher, 1996: p. 16).

ESL/ EFL (English as a second/ foreign language) = It can be defined as the use or study of English by speakers with different native languages in English speaking countries. Unlike ESL, EFl refers to the teaching of English in a non-English-speaking region. Such differences occurred "during the development of English in the 1930s." (Harcourt \& Templer, 2005: p.2).

KWIC (Key word in Context) $=$ It is considered the most common format for concordance lines "especially in the phrase" (Collins English Dictionary, 2003).

OHP (overhead projector) = It is a variant of slide projector that is used to display images to an audience. In the definition of dictionary, "overhead projector is capable of projecting enlarged images of written or pictorial material onto a screen or wall from a transparency placed horizontally below the projector and lighted from underneath"(The American heritage dictionary of the English language, 2009).

SLTs (Speech-Language Therapists) $=$ They are specialized in communication disorders as well as swallowing disorders. They are also called Speech Pathologists (Block et al., 1993, P. 23)

SPSS (Statistical program/package/product/ for social sciences/ and service solution) $=$ It is a 


\section{Macrothink}

Journal for the Study of English Linguistics

ISSN 2329-7034 2013, Vol. 1, No. 2

software package used for statistical analysis and is among the most widely used programs for statistical analysis in social science. Levesque (2007) listed some statistical operations that are normally undertaken by SPSS software. These include: "Descriptive statistics (Cross tabulation, descriptive frequencies, exploration, etc.), descriptive ratio statistics, bivariate statistics (means, t-test, ANOVA, correlation (e.g., bivariate, and partial distances), and nonparametric tests.), and prediction for numerical outcomes (linear regression and prediction for identifying groups (actor analysis, and cluster analysis.) (Levesque, 2007: p. 392).

\section{Copyright Disclaimer}

Copyright reserved by the author(s).

This article is an open-access article distributed under the terms and conditions of the Creative Commons Attribution license (http://creativecommons.org/licenses/by/3.0/). 